\title{
A new infrastructural-relation model for the post-earthquake city of L'Aquila
}

\author{
B. De Vico, D. Di Ludovico \& S. Colagrande \\ Department of Civil, Building-Architecture and Environmental \\ Engineering, University of L'Aquila, Italy
}

\begin{abstract}
Today, when the social model that produced contemporary cities is highly challenged, city models need to be revised, together with the "urban and territorial frame," especially the infrastructural model. The new city model asks for an updated infrastructural, relational and settlement system. Theories about urban regeneration and sustainability, are pointing in this direction. This research aims to find a new role for the infrastructural-relational system, in the context of an innovative idea of the city as well as the society living within it. Fields of interest are: analysis of spatial configurations, new approaches to city re-planning, a new conception of urban infrastructures, and the possible role of infrastructures in a stage of conceptual change, like that of European cities. The main aim is to define a specific way to redesign the infrastructural-relational system inside the contemporary idea of a city, and to redefine urban system planning, basing it on the main project of its own frame. This is possible by applying innovative tools, which care about risks that affect the city, current social changes, and transformational tendencies aimed at preservation. In this context, the city of L'Aquila, Italy is a highly effective example: after the 2009 earthquake which ravaged this city, there have been a series of fast transformations as a result of the urgency of facing this emergency. Instead of continuing with haphazardly chosen solutions, there is great potential for a city like L'Aquila to be the central focus of a conscious re-planning, according to innovative structural models, which respond to the needs of contemporary society.
\end{abstract}

Keywords: infrastructural system, new city model, re-planning, regeneration, sustainability, earthquake, urban framework. 


\section{Post-urban city}

In 1995, the regions of Italy started a remarkable season of experimenting with new laws concerning the management of their own territories; these laws, however, gave birth to planning systems, which did not simplify the creation of efficient decisional chains. Partial justification for this inefficiency is the lack of cooperation between the severed protections of the State and the structured form of evaluation (SEA, EIA) applied to plans and projects. This is because the evaluation of plans and projects is often done only inside the proceedings and without reference to the cognitive and evaluative shared framework. Moreover, the lack of common social models of development, both on a State and a local level, have fueled transformation processes that were clearly "unplanned" and unsustainable, encouraging patchy, diffuse, linear, porous, etc. settlement patterns, which have been widely studied by urban geography.

Complex planning tried a simplification strategy, but often it translated to deregulation, or haggled urban planning by Archistars. This resulted in urban sections conceived and built by an architecture of episodic, isolated, decontextualized nature, determined settlement scatterings, sprawl, rarefaction, high soil waste, fragmentation of environmental nets, assault to the urban landscape and zones of rural-urban transition. All these occurrences in turn determined chaotic urban development on flawed infrastructural frames. Those processes have heavily changed regional settlement systems, especially those with the highest rate of metropolitanization, now presenting unprecedented post-urban shapes difficult to comprehend and even more difficult to manage.

Inconsistency between the social model of development and management of territory tools has therefore produced forms of urban settlement, sometimes called post-urban, which have been analyzed according to classic explanation patterns and models including linear city, sprawl, continuous city, infinite city, periurbanization and so on, which are not matched by transformations nor balanced and sustainable urban and territorial development. Planning systems have not been able to manage these new forms of settlement, but only the traditional processes of transformation, producing more or consolidating new peri-urban morphologies [1].

In this way, new "spontaneous" settlement patterns emerge and articulate themselves related to new uses and more often material streams flowing through territories, concentrating themselves along infrastructure and close to new extraurban centres. For example, instances like the well-known Veneto sprawl, or linear city on the Adriatic Coast, which extends from Emilia to Abruzzo, are complex post-urban settlements which shared an endogenous model of social development. The model of the "third Italy" of the North-East, the one of the great infrastructural streams [2] and the one of the small and average-sized industries settled near to the big industrial centres at the time of the major cities metropolitanization [3] are all examples of post-urban endogenous settlements.

The occurrence of new "spontaneous" settlement patterns has assumed dimensions not covered by planning, and, even with the continuity and uniformity 
of the processes, it shows an internal polymorphism and its own inner rationality, deriving itself unintentionally from the rationality of the plans.

\section{Towards a new model of the city}

Every model is born from need. A city model can be seen as a representation of the reality in order to reach specific goals and satisfy specific needs. A model is a guide to the reading of a territory and consists of a network of concepts, namely the essential characteristics of the territory itself. Every age gave birth to a different urban model generated by needs, habits, aims of the users and from the different shapes of territory and landscape as well. Whether welcoming, defending, linking, meeting, every city hides intentions of communication.

Today, when the social model that produced the idea of a contemporary city is highly challenged by new emerging models, the model of a city needs to be revised, along with the "urban and territorial frame" and, more specifically, the infrastructural model, concerning both roads and technologies. Aware of both past and current evolutions, the new city model is more and more related to the themes of restoration and regeneration. The complexity of the occurrences which rule society and the contemporary city impose new, smart methods, and ask for a reconceptualization of the city model. Looking in this direction, we find all those theories which aim to a new way of conceiving the existing city, such as the reduction of soil consumption, urban regeneration, smart city, smart territory, sustainable mobility, new roles of public spaces and peri-urban rural spaces, safety, governance and government and so on, and to a re-thinking of the urban and territorial framework, and in particular to the role of infrastructural and relational systems.

In the past, the city was at the center of processes of expansion in the territory and often had very little control; today, theories centered on planning are evidencing trends which go to the opposite direction. All the main elements of the new model look to sustainability, as well as reuse and reduction of land consumption. Thanks to massive usage of new technologies for communication, mobility, environment and energetic efficiency, the aforementioned concepts find their application in planning strategies for optimization of public services so as to relate the physical infrastructure of the city with the human, intellectual and social capital of the city's inhabitants, which have led to an improvement in the quality of life and satisfaction of the citizens. The city context includes not only digital infrastructure (mobility, energy distribution, telecommunications, public services) but also the creativity of their community and their institutions. Public space must be the leading character of this model. Public spaces are the material texture, the support for movement of people and vehicles, on which depend the functioning and the livelihood of the city. Looking to public spaces as a continuous, articulated and integrated system is essential: this system should develop from neighborhood relationships to the great environmental systems, in order to encourage their enjoyment and improve urban quality [4]. The urban system of public spaces, seen under a "smart" point of view (as proposed by the European and Italian Urban and Territorial Agenda [9]), is a network of places for collective living, and thus it 
needs an ensemble vision able to make those spaces usable, and add to them attractive features of the urban landscape, enlightening what has to be commended and communicated.

The inner texture which keeps the entire system coherent is certainly the infrastructure network. This paper aims to address this theme highlighting three critical conditions: infrastructure vs. city, infrastructure vs. landscape and infrastructure vs. ecology.

An infrastructure network must grow in the context of a new conceptualization of "relation", according to the needs of the new society (or "liquid society", as sociologist Bauman described it [5]) and it must be developed in an ecologylandscape direction, where ecology means also "energy" and the landscape we think about is "urban" landscape too. The meaning of sustainable mobility, which is too often strictly bounded to the reduction of pollutants produced by vehicles, has to be widened; it must address "connectivity" as a multi-relational framework able to make coherent the textures, cyberspaces, places but also transportation systems interested by different fluctuations (material ones - vehicles and pedestrians, and immaterial ones - technologies), without forgetting a landscapebased urban reuse.

\section{The role of infrastructural system for a new way of conceiving the city}

Infrastructure systems, referring not only to mobility but also to transportation, communication and more broadly to relationship development, have been the texture, the regulatory scheme of the entire urban structure since the first examples of cities arose. The different metamorphoses which involved the model of the city during the succession of historical periods involved first of all these infrastructural-relational systems, which adapted to the contingent needs, have had substantial repercussions on what is the actual urban structure of the city.

Today, the infrastructural-relational system is regaining its role in the connection between the city and the territory, aiming to complete territorial frameworks and connect the flows moving throughout the networks of cities. In the urban sphere, the goal is to reduce and organize the flow of traffic, strengthen public transportation and pedestrianization, and push vehicle traffic out of the urban system.

In this context, fields of interest are: analysis of spatial configurations, new approaches to city re-planning and urban regeneration, a new conception of urban infrastructure (in an "ecological" and "landscape-oriented" sense), and the possible role of infrastructure in a stage of conceptual change, like the one European cities are passing through.

\subsection{Infrastructural system and re-planning an existing city}

Redesigning the model of a city looking to the future means that a balance between consumption and regeneration of the landscape as well as sustainability must be kept in mind. In the new idea of a city, innovation and development do not affect 
local identity, but are in its service. Several of the main goals in this new city model are the relationships between people and the relationships between people and the places where they live, that is social cohesiveness and general well-being.

The leitmotiv of this process is often pinpointed in the infrastructural-relational system: once one highlights the needs, pinpoints possible solutions, and makes clear choices, the infrastructural system will be the connective tissue between the regenerative interventions on the existing city, spreading the action equally on the whole territory.

In the new idea of the city, the infrastructural-relational system shall:

- relieve the congestion of vehicle traffic around the city center;

- make regenerated area of the city easily approachable;

- foster pedestrianization;

- foster soft-mobility;

- foster the use of sustainable vehicles;

- make the growth of public transportation easier;

- be integrated in the landscape, not contrasting with it;

- be associated with the production of renewable alternative energy.

This is possible giving particular attention to ecological-environmental compatibility of the existing infrastructure system, (mobility infrastructure and technology infrastructure) and by controlling acoustic and electromagnetic pollution. Such example of this include privileging non-polluting, low energy consumption technologies making the regenerated infrastructure self-sufficient, creating a parallel relational system capable of satisfying the needs of users, and fully respecting the landscape.

An infrastructure system should be placed into an overall idea of the urban territory, in which a planning confined to single zones, does not appear to be more suitable; this idea finds in the Master Plan its very own tool, able to provide an overall model for the planning of the city-territory, implemented through Urban Planning Projects [10], projects which differ from urban design project, and address the entire urban system. With a global point of view like the one modern society is inclined to take, the city and its vital parts should be considered inside a broader context, like the regional, national or international ones. One of the goals of the new city model is the planning of a network to be an integral part of an infrastructural framework on the large territorial scale, capable of absorbing heavy traffic, projecting new connection with existing and planned urban networks, searching for ways to use new models for its locations, nodes and areas. During the re-planning of the city, the infrastructural system as a whole will be thought of as a macro-region in which every element is indispensable for the right layout and the efficiency of the whole ensemble. This way, the whole city will be a nucleus of a large-scale territorial structure, and its infrastructure will be relevant to the cohesiveness of the urban layout on a local and a national scale.

\section{A case study: the City of L'Aquila}

An effective example of replanning an existing city affected by sudden evolutionary processes is the one concerning the city of L'Aquila. Due to the 
earthquake on April 6th, 2009 the city was touched by a strong and fast transformation, impromptu actions were born from the urgency of dealing with the emergency, and thus were often irrational. This led to "temporary" interventions which deeply changed the arrangement of the territory, and which have actually become permanent in practice.

\subsection{Planning for the emergency}

On April $6^{\text {th }}, 2009$, at 3:32 AM, an earthquake of magnitude (Mw) 6.3 affected the city of L'Aquila and the neighboring areas; casualties included 308 dead and about 1600 wounded. After two weeks, there were about 63,415 displaced people [6]. It was the first time since the Messina earthquake in 1908 that a seismic phenomenon hit a highly urbanized administrative center. Although the earthquakes in the last half century, from Belice (1968) to Umbria-Marche (1997), affected large territories, they had a much lighter impact on the urban structure than did the L'Aquila earthquake. In L'Aquila, the earthquake not only destroyed private houses, it caused severe damage to material and immaterial infrastructure of the society of L'Aquila. The most devastating effects were on public and private real estate, the cultural and architectural monuments and on the primary infrastructure and network of roads; however, damages to the economic system and social cohesiveness of the community were no less remarkable. The territorial-social structure of the city was predominately affected by the destruction of the historic center. Since ancient times, L'Aquila's historic center was the fulcrum of the city, a magnet for the entire urban system. It was the heart of both the economy and the efficiency of the community as well as served as the cardinal element of the inhabitants' identity, thanks to its centripetal force, its architectonical quality, and its administrative and functional role. However, peripheral areas and neighboring territories, strongly damaged themselves, should not be ignored [7].

The authorities who had to intervene right after the disaster found themselves operating with the awareness that they needed to face an emergency situation and that their actions would affect an important urban center.

Policies implemented right after the earthquake focused almost entirely on the housing issue, neglecting the natural complexity of a reconstruction of the historic center, which not only concerned buildings but also urban and territorial systems. These tendencies led to a series of interventions on the territory which heavily changed the urban arrangement of the city, giving it its current shape. Said interventions can be summed up as follows:

- C.A.S.E. project - Complessi Antisimici Sostenibili Ecocompatibili (Aseismic Sustainable Environment-friendly Units); urban projects which have been realized through new districts in 19 areas, 4,500 apartments, 185 buildings, covering around 15,000 inhabitants [6];

- M.A.P. - Moduli Abitativi Provvisori (Temporary Housing Units); also in this case, they are urban projects, which led to the creations of new urban agglomerations in the suburbs of 27 areas: 1273 units, for about 3,000 inhabitants [6]; 
- M.U.S.P. - Moduli ad Uso Scolastico Provvisori (Temporary School Units); these are the schools realized on the outskirts after the earthquake; they are home to approximately 5,500 students from 25 areas [6];

- Resolution of the City Council No. 58 of April 25th 2009; this is the resolution of the City Council entitled "Criteria for the location and construction of temporary artifacts" that led to the creation of residential or productive artifacts, often "not just temporary" throughout the municipality, "in derogation from the rules concerning landscape and environmental areas, including those that record the presence of "tratturi", ancient pastoral pathways"; a first estimate identifies approximately 2,000 units [1].

These four post-earthquake measures have dramatically changed the urban fabric of L'Aquila. In general, the measures created residential buildings for about 21,000 inhabitants, plus schools for 5,500 students and temporary houses for about 5,000 inhabitants. L'Aquila, a city of 26,000 inhabitants, was re-built in six months. However, this post-earthquake city is a city outside the city, without relationship with the historical, consolidated city and it breaks from the existing fabric of what L'Aquila really is.

The post-earthquake settlement dynamic in L'Aquila followed two patterns. On one hand, redevelopment was executed based on the logic of compromise knowing that damage would have to be done to the contained and esteemed urbanperipheral areas. On the other hand, new development also followed the logic of sprawl and partook in soil consumption in the unused agrarian areas, making sure to protect the continuity in biological-vegetation, which is an essential component in maintaining the natural landscape of the region.

These patterns had serious repercussions on the infrastructure system, which had developed over time to meet the needs of a centralized city, and now found the need to convert itself to serve an urban center which had completely changed its organization. It is the function of the infrastructure itself that changed after the earthquake: especially meaningful was the transformation of what was a crossing route of the city (SS17).

This phenomenon of non-planning, led more by the principles of fast intervention and urgency than by the principle of quality, combined with the devastating effects of the earthquake has led to the cancellation of some of the key features that have always marked the city.

\subsection{The post-emergency non-planning}

Five years after the earthquake, the city of L'Aquila appears with a shape totally different from the original, pre-earthquake one. The birth of the so-called new towns (urban agglomerations of the C.A.S.E. project) in the suburbs, and the displacement of a range of equipment and services from the center to new peripheral locations, have deeply changed the urban structure of the city, thus requiring a new qualification and a new structure of the infrastructure system in the context of the urban framework. Despite the urban expansion of L'Aquila preearthquake, it was easily accessible, and preserved a direct relationship between town and country (the old town, thanks to a system of natural greenery that 
surrounded it to the east and south, interacted directly with rural areas) and could rely on a central urban core, formed by the most valuable spaces and urban functions, which served as a real magnet for the ninety-nine villages of the municipality. In contrast, the post-earthquake urban structure of L'Aquila has a linear development that runs from east to west along one of the main thoroughfares, the SS17. Inside the new urban order, it is impossible to determine a new city center, and there are a number of centers interacting with each other by systems; post-earthquake L'Aquila is a polycentric city including several subsystems:

- Polygonal subsystem;

- Circular subsystem;

- Radial subsystem;

and the only feature they share is the same direction of development; East-West.

Immediately after the earthquake, the priority of authorities was to provide urgent assistance to the population, especially providing adequate accommodations. However, this does not justify the lack of post-earthquake planning which would be capable of regulating a series of occurrences in the territory consecutive to: earthquake, new settlements.

At the end of the emergency, there was indeed a need for timely post-event planning with objectives and policies for the short term. However, this cannot be a reconstruction plan nor a new PRG (a local development frameworks), but should be a simple structural and strategic tool, such as the Master Plan, practicable through Urban Planning Projects (long and short-term too). In the case of L'Aquila, the situation is exactly the opposite; post-earthquake non-planning has led to a vicious process in which on one hand a number of critical issues are identified, and on the other hand the government is trying to solve the issues with spot-interventions that do not turn their eyes to a wider view.

In this sense it is therefore still necessary to define a short-term view of the city, between emergency and reconstruction, linked to effective and rapid implementation tools such as urban projects. A specific theme that the projects will have to address in a modern and contemporary idea of L'Aquila is the basic theme of infrastructure, which should solve the following problems:

- traffic congestion along the major infrastructure networks of the city;

- lack of an infrastructure system capable of accommodating the new traffic flows generated by the new structure of the city;

- inadequacy of the existing infrastructure to meet the need of citizens to travel long distances to access basic services which the new towns are lacking;

- uneven distribution of residential neighborhoods;

- presence of settlements, in the same areas, relating to different activities (e.g. residential, industrial ) inconsistent to each other;

- worsening of pre-existing problems regarding the proper connection between L'Aquila and the surrounding territories;

- high impact of infrastructure on the landscape, presumably due to inefficient evaluation at the design stage. 


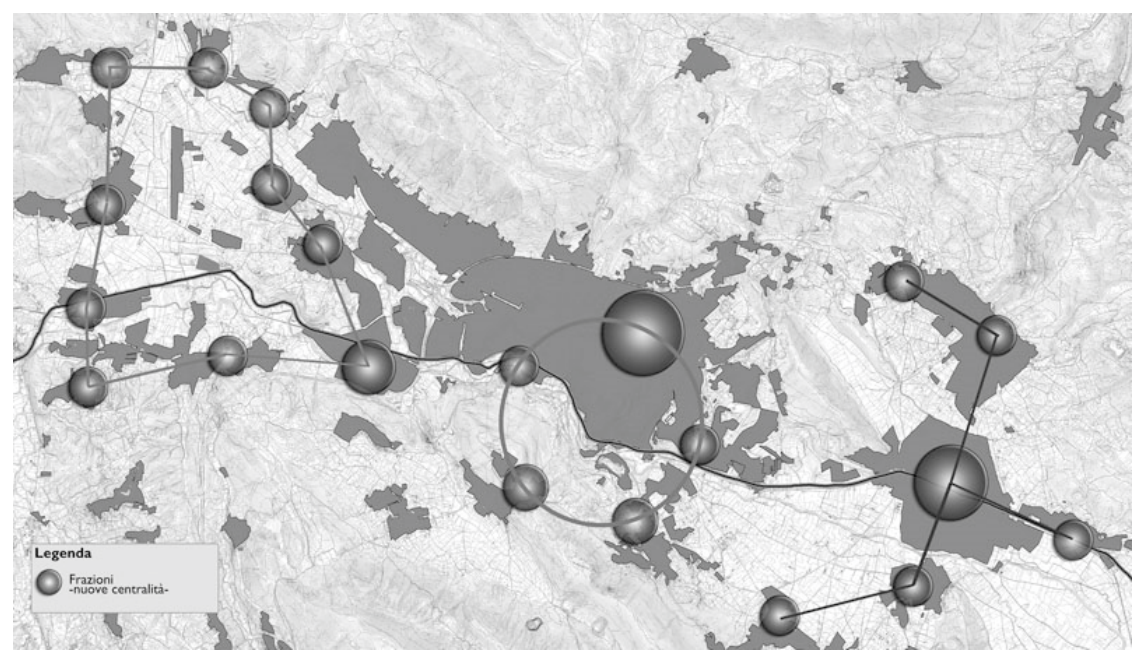

Figure 1: Polycentric system in post-emergency L'Aquila.

These critical issues need to be addressed with a comprehensive approach that takes into account reconstruction as an act of urban regeneration, exploiting and systematizing all local interventions that are heavily transforming the city of L'Aquila. "Systematization" means directing a non-planned transformation to the consistency of all urban events by tools as the master plan and the urban planning project, providing integrated solutions to the critical issues, such as those aimed at the integration of the infrastructure system in the urban texture (also as an urban and regional framework).

\subsection{The Urban Planning Project for a new concept of infrastructural system}

This case study highlights the need for a comprehensive point of view on the development (and in the specific field of urban systems, the need to intervene through a general plan), able to direct and channel all those episodes of Urban Planning Projects in an overall view. The perspective is a model of government, decisive for the new city model, capable of solving all the problems and the conflicts inherent in the rigid and static current planning systems. A model that adopts the theory of the regeneration of the territory, takes into account sustainability but at the same time the quality of life of those who live there and conceives the territory as an integral part of a large-scale system.

As already mentioned, a model that could be effective for the city of L'Aquila after the earthquake is the use of the "Project", which is the creation of a territorial assets through the implementation of urban projects (not plans). "Project" is a much more effective tool in the short term than the Reconstruction Plan and the classical PRG (local development framework). A project is also able to bring into play the parts of the consolidated city with actions of requalification, promoting social recomposition processes, and allowing the tangles of the urban spaces and urban environmental networks to be mended through the recognition and use of 
urban voides (residues of a reformist planning). In this new design approach, which hosts a wide range of items to consider (natural connective tissues, mobility, centrality, structuring paths, et cetera.), the theme of urban and territorial framework is of particular relevance along with the related infrastructure system (and therefore the public space); the large urban systems (production, trade, residence, facilities) are arranged within the framework, in which disjointed institutional models and social models live together.

The establishment and organization of public space, and more generally of the new urban and territorial framework, compete as a priority in the new model; within the model the new infrastructural-relational system should be structured and connected to the bigger territorial frameworks, in accordance with the principles of sustainability and low consumption of the land. The new model should also determine a new governance for a faster realization of projects and a new relationship between the institution and the citizen in order to share and evaluate them: essential elements to the social cohesiveness and to the construction of a local and regional identity, of a society as dynamic as its territory and its cities [1].

In this sense, thanks to the research on a new model of urban and territorial framework, innovative paths of research are in development for small cities like L'Aquila, a city taken as a reference because it was affected by post-earthquake reconstruction and therefore by a transformative acceleration that can allow experimentation in a short time through the tool of a project.

In general, the goal is a government action for urban and territorial transformations, addressing the theme of eco-town. In particular, the issue addressed relates to a new role for the infrastructure system, developed in terms of:

- Urban regeneration, combined with issues such as densification, urban infilling, recovery of abandoned and degraded areas, role of the empty spaces, but above all with an innovative interpretation of public space and of the infrastructure system, also linked to issues such as pedestrianization and soft mobility;

- Mobility and Transport Infrastructure vs. Green and Grey Infrastructure [12]; when you consider the city in terms of eco-town, a contradiction which must be investigated shows up between the green infrastructure and the infrastructure for urban mobility, a topic of particular interest in a city surrounded by nature as L' Aquila is;

- Smart City, Smart Infrastructure and Smart Mobility [13], which bring with them issues as energy transportation and production, infomobility and traffic optimization, management of urban logistics (including waste management), reduction of pollution;

- New techniques of road infrastructure design, related to the use of new materials and to new models of road traffic, to an eco-friendly relationship between roads and buildings, to systems of autonomous driving and new standards of performance and service levels; 
- Assessment of the urban infrastructure system, through indicators such as Walkability, Pedestrian index, Sustainable Transportation Access Rating System, etc [8];

- Configurational analysis (Space Syntax Analysis) [11], which helps to understand the critical issues of the urban texture and can be used, with the above mentioned goals, in terms of projects.

The combination of these themes, an intervention to innovate an inefficient existing infrastructure network, and more generally the post-urban city, can help generate a new city adherent to contemporary social patterns, and this can only be done through the "Project".

\section{Conclusion}

This paper has described an ongoing process of research about a new role for the infrastructure system of the contemporary city of L'Aquila, a small-medium sized example of one of Central Italy's post-urban cities: we tried to highlight how L'Aquila could represent an ideal case to apply new models of urban development because it has been shaken in its structure by a series of events (earthquake and unplanned reconstruction). It is an ideal testing ground because the new models of urban development are compatible both with environmental requirements and with the need to improve the quality of life of L'Aquila's citizens.

In order to govern the simultaneous process of change and rebirth of the city, it is essential to direct the tools of urban and territorial transformation towards critical issues and needs such as targeted projects to overcome the traditional instruments of planning that led to the current inefficient urban forms, and to requalify existing structures serving as a guideline for future ones.

In terms of infrastructure, there are many issues to address and they often relate to other themes such as urban regeneration, resilience, green infrastructure, energy, and the smart city. Thinking of a "regeneration" of the existing urban infrastructure system in terms of eco-sustainability means it is necessary to investigate such things as regulating traffic streams in order to make cities more liveable. There must also be attention to possible development of eco-sustainable buildings, energy efficiency, reduction of waste, and the promotion of public transport. This will advocate a living relationship between the urban environment and the natural landscape and will best integrate new public spaces with contemporary reinterpretation of existing ones.

The combination of these issues, as seen in the need to rebuild L'Aquila, can help create a new city adherent to contemporary social patterns, which can only be done through the "Project", which in this case could be defined as a "project of urban and territorial framework."

\section{References}

[1] Di Ludovico D., Properzi P., Progetti urbani e Progetti urbanistici nel governo dei paesaggi post-urbani, proceedings of XV Conferenza Nazionale SIU - Società Italiana degli Urbanisti - L’Urbanistica che 
cambia. Rischi e valori, Pescara May 10-11, 2012, Planum, The Journal of Urbanism www.planum.net n. 25 vol.2/2012.

[2] Castiglioni B., Ferrario V., Dove non c'è paesaggio: indagini nella città diffusa veneta e questioni aperte, in Rivista Geografia Italiana, CXIV, 3, pp. 397-425, 2007.

[3] Scott A. J., Agnew J., Soja E. W., Storper M. (2000), Global city-regions, in Global City-Regions, Trends, Theory, Policy, Edited by Allen J. Scott, Oxford University Press, Oxford 2001.

[4] BSP, Carta dello Spazio Pubblico 2013, Biennale Spazio Pubblico May 18, 2013, http://www.biennalespaziopubblico.it/blog/blog/carta-spaziopubblico, 2013.

[5] Bauman Z., Modernità liquida, Ed. Laterza, Roma-Bari 2002.

[6] DPCN, Terremoto in Abruzzo, http://www.protezionecivile.gov.it/jcms/it/ emergenza_abruzzo.wp

[7] Frisch G. J., Il terremoto dell'Aquila. Pianificazione dell'emergenza e urbanistica, Università di Camerino, Facoltà di architettura di Ascoli Piceno 2010.

[8] Bye J., Creating a Street Vitality Index, Analysis of existing street rating systems and recommendations for the future, working paper, 2012.

[9] EU, Territorial Agenda of the European Union 2020, towards and Inclusive, Smart and Sustainable Europe of Diverse Regions, http://www.eu-territorial-agenda.eu/Reference\%20Documents/Final\% 20TA2020.pdf, 2011.

[10] Morandi M., Progetto urbano e progetto urbanistico: riferimenti $e$ considerazioni, in Macramè n. 3/2009, on-line magazine of the University of Florence, pp. 85-88, 2009.

[11] Hillier B., Space is the machine, A configurational theory of architecture, Space Syntax, London, 2007.

[12] LI, Green Infrastructure, An integrated approach to land use, Landscape Institute, London, p. 4, 5, 16, 2013.

[13] EHA, Smart Mobility, muoversi meglio per vivere meglio, working paper, The European House Ambrosetti for Finmeccanica, 2012. 